\title{
Consensus statement of the Italian society of colorectal surgery (SICCR): management and treatment of pilonidal disease
}

\author{
M. Milone $e^{1} \cdot$ L. Basso ${ }^{2} \odot \cdot$ M. Manigrasso ${ }^{3} \cdot$ R. Pietroletti ${ }^{4} \cdot$ A. Bondurri ${ }^{5} \cdot$ M. La Torre ${ }^{6} \cdot$ G. Milito $^{7} \cdot$ M. Pozzo $^{8}$. \\ D. Segre ${ }^{9} \cdot$ R. Perinotti ${ }^{8} \cdot$ G. Gallo ${ }^{10}$
}

Received: 20 May 2021 / Accepted: 12 June 2021 / Published online: 27 June 2021

(c) The Author(s) 2021

\begin{abstract}
Pilonidal disease (PD) is a relatively common, benign but challenging condition of the natal cleft. This consensus statement was drawn up by a panel of surgeons, identified by the Italian Society of Colorectal Surgery (SICCR) as having a "special interest" in PD, with the aim of recommending the best therapeutic options according to currently available scientific evidence. A three-step modified-Delphi process was adopted, implying: (1) choice of the panelists; (2) development of a discussion outline and of target issues; and (3) a detailed systematic review of the current literature. The agreement/disagreement level was scored on a five-point Likert scale as follows: "A+: strongly agree; A-: agree; N: unsure/no opinion; D-: disagree; $\mathrm{D}+$ : strongly disagree. Each panelist contributed to the production of this manuscript, and the final recommendations were reviewed by the Clinical Practice Guidelines Committee.
\end{abstract}

Keywords Pilonidal sinus $\cdot$ Pilonidal disease PD $\cdot$ Operative management $\cdot$ Minimally invasive approach $\cdot$ Consensus

\section{Introduction}

Pilonidal disease (PD) is a relatively common, benign but challenging condition, normally, albeit not exclusively [1], involving the natal cleft. PD afflicts around 26 people in 100,000 [2], and its ideal treatment is controversial. In 2015, the Italian Society of Colorectal Surgery (SICCR) issued treatment guidelines [3], inspired by those of the American Society of Colorectal Surgeons [4]. However, the current surgical arena has been recently enriched by relatively new

\section{R. Perinotti and G. Gallo equally contributed to this} manuscript. M. Milone, L. Basso and M. Manigrasso shared first author position.

\section{Basso}

luigi.basso@uniroma1.it

1 Department of Clinical Medicine and Surgery, "Federico II" University, Naples, Italy

2 "Pietro Valdoni" Department of Surgery, Policlinico "Umberto I", "Sapienza" University of Rome, viale del Policlinico 155, 00161 Rome, Italy

3 Department of Advanced Biomedical Sciences, "Federico II" University, Naples, Italy

4 Surgical Coloproctology, "Val Vibrata" Hospital, "L'Aquila" University, Sant'Omero, TE, Italy surgical approaches and new evidence. Therefore, the Italian Society of Colorectal Surgery (SICCR) put together an expert consensus statement based on the available literature.

\section{Methodology}

The present consensus statement was drawn up based on the opinion of a panel composed of surgeons identified by the Italian Society of Colorectal Surgery (SICCR) as having a special interest in $\mathrm{PD}$, with the aim of identifying the best therapeutic option(s) to treat PD, according to currently available scientific evidence. The consensus was drawn up

5 Department of General Surgery, ASST Fatebenefratelli Sacco, "Luigi Sacco" University Hospital, Milan, Italy

6 Coloproctology Unit, "S. Anna" Clinic, Pomezia, RM, Italy

7 Department of General Surgery, "Tor Vergata” University, Rome, Italy

8 Department of General Surgery, "Degli Infermi” Hospital, Biella, Italy

9 General Surgery Operative Unit, "Città di Bra" Clinic, Bra, $\mathrm{CN}$, Italy

10 Department of Medical and Surgical Sciences, "Magna Graecia" University, Catanzaro, Italy 
according to a modified-Delphi process (5), characterized by three principal steps: (1) choice of panelists, (2) development of a discussion outline and of core issues, and (3) a detailed systematic review of the current literature.

To ensure the inclusion of all available studies, a detailed search for PD was performed in the electronic databases (PubMed, Web of Science, Scopus, EMBASE) with several combinations of keywords: pilonidal sinus, pilonidal sinus disease, etiology, risk factors, diagnosis, surgery, open healing, VAC-therapy, drainage, midline, off-midline, flap, Limberg, Karydakis, minimally invasive treatment, sinusectomy, sinotomy, Gips, endoscopic pilonidal sinus treatment (EPSiT), video-assisted ablation of pilonidal sinus (VAAPS), satisfaction, recurrence, infection, epilation. The literature search included all papers published through July, 2020.

In May, 2020, the invited panelists were asked to agree/ disagree with statements based on the current literature, and to submit any comment(s) in case of disagreement. These statements addressed the most important PD related issues, such as: classification, diagnosis, surgical treatment of acute, chronic, and recurrent PD, perioperative management. Each statement was graded according to the criteria adopted by the American College of Chest Physicians, summarized in Table 1 [6], and taking into consideration the relevance of the various levels of evidence, and grades of recommendation.

The agreement/disagreement level was scored on a fivepoint Likert scale as follows: "A + : strongly agree; A-: agree; $\mathrm{N}$ : unsure/no opinion; $\mathrm{D}-$ : disagree; $\mathrm{D}+$ : strongly disagree [7].

Each panelist contributed to the production of this manuscript, and the final recommendations were reviewed by the Clinical Practice Guidelines Committee.

An external reviewer examined the answers provided, and, in case of disagreement, the statements were modified and submitted again to each panelist until complete accordance was reached. Each expert contributed to the production of this manuscript, and the final recommendations were reviewed by the Clinical Practice Guidelines Committee of SICCR.

\section{Classification}

\section{No widely used classification of PD has been developed} (1C)

Data about classification of PD in the current literature are scarce, and there are no randomized controlled trials evaluating the impact of sinus characteristics on the surgical choice and on surgical outcomes.
A systematic review of the classification systems for PD was performed by Beal et al. [8], considering seven studies [9-15] and featuring several characteristics, including: the presence of a single pit or of multiple pits along the midline, the presence of unilateral or bilateral pits near the midline, the presence of lateral pits within or outside the navicular area as defined by Tezel [13], the recurrence of PD, or the presence of an abscess. Only one classification system recorded the patients' features as well as characteristics of the disease [14]. Only the location of the sinus was present in all classifications.

Expert statement: there is no validated classification of PD, even if sinus characteristics may modify surgical decision making and postoperative outcome. Features to be considered should cover: number of pits, their location in relation to midline, distance of the most caudal pits from the anal verge, and the presence of previous incisions or scars. [complete agreement at 2 nd round]

\section{Diagnosis}

\section{Diagnosis is based on clinical aspects, physical} examination, and disease-specific history (1C)

The diagnosis of PD is mainly clinical, based on signs, symptoms, and physical examination. Patients often complain of severe pain or swelling in the sacrococcygeal area, and, in case of an acute abscess, fever may be an additional symptom.

Physical examination often shows the presence of pits along the natal cleft and/or on the buttocks, far from the midline. Routinely, diagnostic imaging and laboratory tests are not necessary. However, in rare cases, especially in those near the anal verge, it is important to distinguish PD from other perianal conditions such as: cryptogenic perianal fistula, septic anal fissure, gluteal abscess, hidradenitis suppurativa, Crohn's disease, ulcerative colitis, syphilis, tuberculosis (TB), epidural abscess, other soft tissue infections (folliculitis, furuncles, or carbuncles, etc.), dermoid cyst (teratoma or germ cell tumor). In these cases, a thorough anorectal examination, a proctoscopy, a trans-rectal ultrasonography, or other diagnostic imaging examination should be performed to exclude or to confirm diagnosis of PD [16-18].

Panel statement: the diagnosis of PD is clinical, although anorectal examination or diagnostic imaging should be performed in case of $P D$ near the anal verge, in order to rule out or to confirm the presence of other anorectal disease(s). [complete agreement at 2 nd round]. 


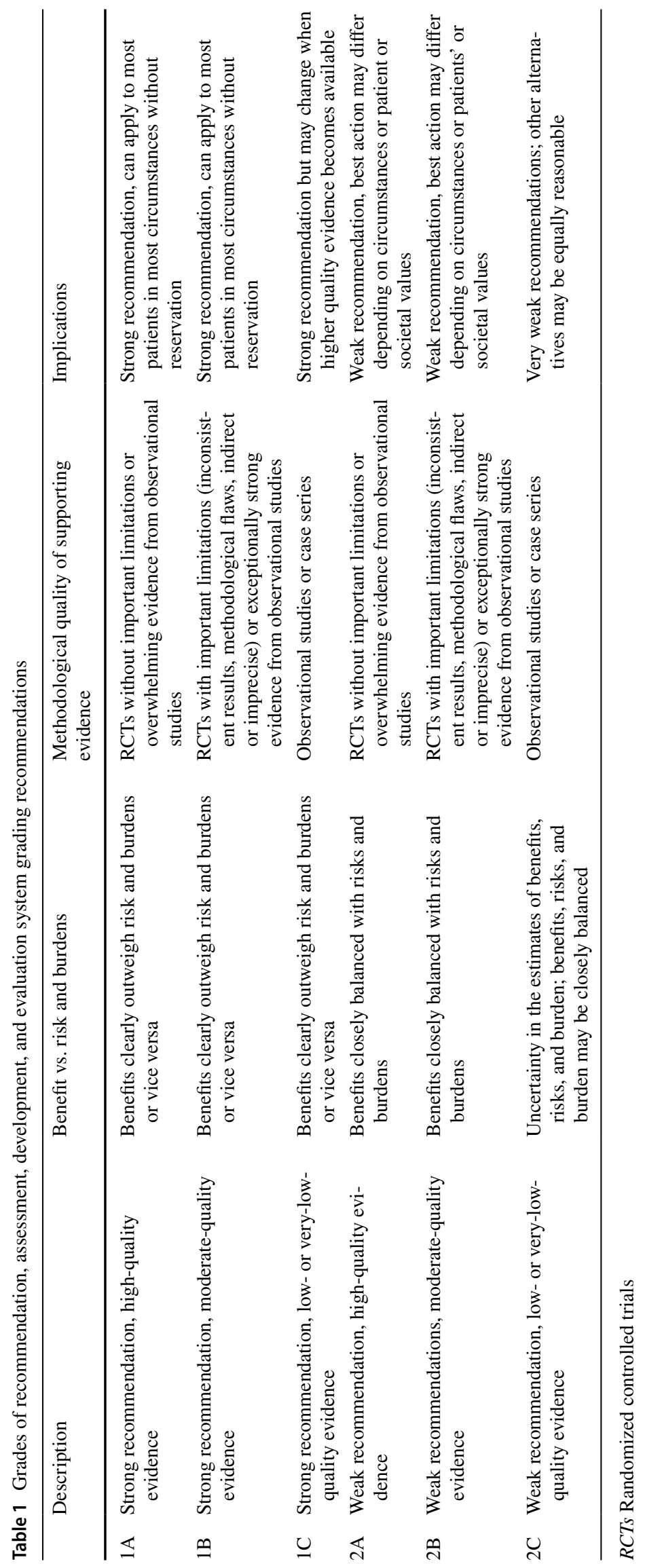




\section{Operative management}

The mainstay of treatment of an acute pilonidal abscess is simple incision and drainage, regardless of whether it is a primary or recurrent episode. Debridement or primary excision of the pilonidal abscess would be ideal, but depends on the clinical setting. (1B)

Acute pilonidal abscess usually presents with redness, tenderness, pain, and the presence of a fluctuant area in the sacrococcygeal region, sometimes with fever. At this stage, usually all that can be done is simple incision and drainage of the abscess [19]. However, this procedure fails to cure the chronic inflammation due to the foreign body reaction typical of PD, leading to an elusive and temporary healing with re-epithelization of the sinus tract [20]. Therefore, simple incision and drainage carry a recurrence rate up to $42 \%$, which compels these patients to need and seek an additional and, hopefully conclusive, treatment [21].

Several primary treatment options have been described for the conclusive treatment of the pilonidal abscess. First, in a randomized controlled trial (RCT) comparing simple incision and drainage with or without debridement of the sinus tract, debridement was associated with a higher complete healing rate at 10 weeks (96 vs. $79 \%, p=0.001$ ) and a lower recurrence rate after a follow-up of 65 months (11 vs. $45 \%, p=0.001)$ [21].

These results were recently confirmed by a meta-analysis of debridement and laying open, which showed a recurrence pooled rate (DerSimonian and Laird random effects) [22] of $4.47 \%$ (95\% CI $=0.029-0.063$ ), in both acute and chronic PD [23]. Matter et al. [24] compared drainage alone with primary excision of a pilonidal abscess. The recurrence rate was 55 and $41 \%$, respectively. In a comparison between drainage followed after 3 weeks by excision and primary closure with excision and secondary healing, Hosseini et al. [25] demonstrated a higher recurrence rate of the abscess ( 14 vs. $0 \%, p<0.05)$ within 12 months after delayed excision and primary closure.

Recently, minimally invasive techniques have been suggested to also treat the acute presentation of PD [26, 27]. For instance, in a small study comparing simple incision and drainage vs. endoscopic pilonidal abscess treatment (EPAT) (20 patients in each group), EPAT seemed to be associated with a shorter time to wound healing (16 vs. 35 days, $p=0.0018$ ), but the same number of cases required further conclusive surgery $(20 \%$ [26] or $21 \%$ [27]).

Panel statement: the standard treatment for acute pilonidal abscess remains simple incision and drainage. Debridement or primary excision of the pilonidal abscess or minimally invasive techniques could, also, be a valid alternative in the individual patient. [complete agreement at 2nd round].

\section{The most appropriate surgical treatment of chronic PD sinus is controversial (1B)}

At least one paper has shown the benefits of open healing over primary closure after the excision of chronic PD in terms of recurrence [28]. On the other hand, the recurrence rate was significantly higher in patients left open compared to patients after Limberg flap (7/15 vs. 1/24 $p=0.005)$ [29], while another research showed a substantially overlapping recurrence rate after Z-plasty and open wound [30].

When comparing "midline" with "off-midline" primary closure, the current literature advocates "off-midline" suturing, at least in terms of surgical site infections (SSI), and recurrence rates [31-33].

The introduction of minimally invasive, "targeted" procedures has significantly changed the surgical approach to chronic PD [34-43]. These techniques (Table 2) were first launched in the " $60 \mathrm{~s}$, and became popular in North America in the 1980s, after Bascom proved that PD is a skin condition, thus providing solid grounds for a "targeted" and minimally invasive surgical approach [35, 36]. Recently, a number of minimally invasive approaches have become popular, parallel to their feasibility and to expectations of both patients and of private or public health services, always trying to minimize costs and favoring less dressings, faster recovery, and prompt return to active work or to school/ university activities.

However, until now, few RCTs have compared these minimally invasive techniques vs. time-honored standard surgical treatments [44-46].

Recently, Popeskou et al. [44], while comparing sinusectomy with off-midline primary closure, had to prematurely interrupt their trial because of the longer wound healing time after sinusectomy, in contrast with the expected results.

While comparing both short- and long-term outcomes of video-assisted ablation of pilonidal sinus (VAAPS) vs.

Table 2 Minimally invasive surgery techniques to treat pilonidal disease

\begin{tabular}{llll}
\hline & Description & Year & Reference \\
\hline 1 & Lord-Millar & 1965 & {$[34]$} \\
2 & Bascom's pit-picking & 1980 & {$[35]$} \\
3 & Sinusectomy & 2002 & {$[38]$} \\
4 & Sinotomy & 2005 & {$[110]$} \\
5 & Punch biopsy & 2008 & {$[40]$} \\
6 & Video-assisted ablation of & 2014 & {$[42]$} \\
7 & pilonidal sinus (VAAPS) & & \\
& Endoscopic pilonidal sinus & 2014 & {$[41]$} \\
& treatment (EPSiT), & & \\
\hline
\end{tabular}


Bascom "cleft lift", Milone et al. [45, 46] demonstrated that VAAPS was associated with shorter time off work and lower postoperative infection rates, less pain, and higher patient satisfaction, with a comparable 5-year recurrence rate.

Finally, a study compared sinusectomy and endoscopic treatment [47], showing that endoscopy was associated with a recurrence rate lower than sinusectomy, but overlapping postoperative pain and patient satisfaction. However, recurrences after sinusectomy were unacceptably high (25\%).

Panel statement: validated operative techniques for the treatment of chronic PD include: open healing, off-midline primary closure, and minimally invasive techniques. [complete agreement at 2 nd round].

In the case of primary closure, off-midline closure should be the treatment of choice. Employment of drains should be tailored to the individual patient (1B)

Six studies compared surgical midline against off-midline closure. Healing times were faster after off- midline closure (MD 5.4 days, 95\% CI 2.3-8.5). SSI rates were higher after midline closure (RR 3.72, 95\% CI 1.86-7.42) and recurrence rates were higher after midline closure (Peto OR 4.54, 95\% CI 2.30-8.96) [48].

A meta-analysis of RCTs, comparing different techniques with primary closure for chronic PD, showed that open radical excision and primary midline closure should be abandoned and that sinusectomy/sinotomy or "en bloc" resection with off midline primary closure should be the preferred approaches [49].

In a long-term analysis, the recurrence rate after open healing, midline closure and off-midline closure was $17.9 \%$, $16.8 \%$, and $10 \%$, respectively. Unfortunately, statistical analysis was not performed, and this study only focused on recurrence [50].

Panel statement: in the case of primary closure, offmidline closure must be considered to be the gold standard because it is associated with better postoperative outcomes compared to midline closure. [complete agreement at 1st round].

Various "off-midline" techniques have been described over the years. The Karydakis flap (K-flap) allows to perform an "off-midline" suture employing a mobilized fasciocutaneous flap secured to the sacrococcygeal fascia. In a survey on 7471 patients treated from 1966 through 1990 and with a follow-up from 2 to 20 years, Karydakis [51] showed a recurrence rate of $1.0 \%$ and a wound complication rate of $<8 \%$. In a recent RCT comparing K-flap with open healing [52], K-flap was associated with a significantly lower time to wound healing, return to work, wound complications, and recurrence.
In the Limberg (rhomboid) flap technique, all sinuses are excised and a rotating lipocutaneous flap is used to lower down the natal cleft [53]. A few RCTs [54-57] and metaanalyses of RCTs [58-60] have demonstrated that Karydakis and Limberg flaps have similar good outcomes in terms of post-operative SSI, return to work, wound healing, and recurrence rate, although the K-flap seems to be related to a higher occurrence of seroma.

The "cleft lift" technique was first described by Bascom in 1987 [61-63], and, following pilonidal excision, is based on the employment of an asymmetrical skin flap to cover deep natal clefts, resulting in a suture off the midline. Initially the "cleft lift" was employed in refractory or unhealed $\mathrm{PD}$, but several cases have shown that it has a role in the primary approach [64-66]. Only one RCT comparing Bascom cleft lift and Limberg flap has been published in the last decade, showing that, although both techniques achieved good results during the early period, the Bascom cleft lift provides shorter operative times and better quality of life during the early postoperative period [67].

Several other flap techniques have been developed over the years, such as the $\mathrm{V}-\mathrm{Z}$ advancement flap, Z-plasty, and parasacral perforator flap techniques. These flap techniques have been successfully employed in the treatment of complex $\mathrm{PD}$, with a complete healing rate $>90 \%$, as reported in a few series [68-70].

In a randomized trial comparing Z-plasty and delayed healing by secondary intention, Fazeli et al. [30] showed that Z-plasty was associated with a shorter time to both wound healing and return to normal daily activities, while there were no significant differences in terms of bleeding, hematoma, infection, and recurrence rate.

Despite these results, it is important to emphasize that these techniques may require general anesthesia, prolonged hospitalization, and surgeons dedicated to these procedures [71].

Panel statement: it is not possible to identify the best off-midline technique, all being validated procedures. [complete agreement at 2 nd round].

Several studies have assessed the use of drains after primary closure [72-75]. The results of a nonrandomized trial have indicated that the employment of drains after pilonidal excision and primary closure was associated with a lower rate of wound healing, without differences in the recurrence rate [72].

In a randomized comparison between employment of drains vs. no-drains after primary closure, Milone et al. [73] demonstrated that drains did not achieve a faster wound healing, and, on the contrary, they were associated with lower patient tolerance. When adopted after flap techniques, drains are associated with a lower incidence of fluid collections but no actual difference in wound infection [74], while Erdem 
et al. showed that Limberg flaps with no drains in place result in shorter hospital stays without deleteriously affecting the surgical results of wide excision and primary closure with well-vascularized tissue [75]. A relatively recent metaanalysis [76] of randomized trials in patients undergoing either Karydakis or Limberg flap tried to identify the association between placement of a drain and the infection and recurrence rates, suggesting that, despite a trend toward a reduction in wound infection and recurrence rates, drains were not associated with overall better outcomes.

Panel statement: when a primary closure is performed, the employment of drains depends on the surgeon's preference and on the individual patient. [complete agreement at 2nd round].

\section{The benefits of open healing vs. primary closure are controversial (1B)}

Traditional surgery for chronic PD can be divided in two categories: excision with primary closure (including midline and off-midline sutures and reconstruction with flaps) and excision with healing by secondary intention (open healing) $[50,77]$.

The 2010 Cochrane Systematic Review [48], compared open healing with primary closure after excision of PD, including 17 RCTs published from 1987 through 2009. The results suggested that open healing was associated with a longer time to wound healing over primary closure (range: 41-91 days vs. 10-27 days). The SSI rate was similar in the two groups. On the contrary, open healing was associated with a recurrence rate significantly lower than primary surgical closure, with a reduction of the recurrence risk of $35 \%$. When assessing time off daily activities, a significant clinical improvement was found in the primary closure group vs. open healing.

A recent a meta-analysis of 5 RCTs compared flap vs. lay open excision [78]. The results showed a non-significant trend toward less recurrences in case of flaps vs. the laying open technique. Time to complete wound healing and time off work were significantly shorter after the flap technique, while the SSI rate was similar within both groups.

In 2014, Enriquez-Navascues et al. [49] performed a meta-analysis of 25 RCTs comparing the results of different open healing and primary closure approaches after excision of PD. In studies comparing sinusectomy/sinotomy versus open "en bloc" resection, no significant differences were found in terms of time to healing and recurrence rate between the two groups, while return to daily activities was faster in the sinusectomy group.

Panel statement: open healing should be limited to complex cases, since the benefits on recurrence are not clear and the postoperative recovery may be longer. [complete agreement at 2 nd round].

Open healing, aside from causing patient discomfort, may require frequent painful dressings, and close clinical observation. Dressings should provide an optimal environment for wound healing, and the so called "advanced dressings" do this by simple physical or chemical means, typically by controlling moisture levels, with the aim of optimizing wound cleansing and re-epithelization (for example, calcium alginate, film, foam, hydrocolloid, and hydrogel dressings) [79-82].

In a recent RCT comparing three different dressing methods after pilonidal surgery [83], dressings with hydrogel or alginate and hydrocolloid compounds reduced the average number of days off daily activities in comparison with Vaseline gauze (modified method dressing) and sterile gauze (standard method). However, so far, no single dressing method has been scientifically proven to be superior to others [84].

A RCT was conducted by Mohammadi et al. to test the effect of platelet-rich plasma (PRP) on wound healing after sinus surgery and showed that PRP was associated with a significantly faster healing process and return to routine daily activities compared to classic wound dressing with sterile gauze [85].

Negative pressure wound therapy (NPWT) was also introduced with the purpose of speeding up the process of wound healing. In a RCT comparing NPWT and standard dressings after open healing, Biter et al. [86] showed that NPWT was associated with faster wound healing within the first two weeks after surgery. However, no significantly shorter time to wound healing and return to daily activities was related to the use of NPWT. On the contrary, NPWT required a longer hospital stay.

Panel statement: in case of wide pilonidal excision and open healing, NPWT is recommended. Advanced dressings could be a valid alternative. [complete agreement at $2 \mathrm{nd}$ round]

\section{Minimally invasive techniques may be safe and effective in the treatment of chronic pilonidal sinus (1B)}

A minimally invasive approach was first described by LordMillar in the 1960s [34]. Later, in the 1980s, Bascom developed the concept of "targeted procedure", aimed at treating and removing only the diseased tissues, leaving alone any unaffected and healthy surrounding tissue. This was based on his solid studies on the origin of PD [35-37]. Later, Oncel, Soll and Gips, while adopting the same principles, slightly modified these "targeted procedures" [38-40].

Oncel, in 2002, first reported sinusectomy to treat limited, chronic PD in a series of 40 patients, with a shorter operation time, hospital stay and period off work than 
excision and marsupialization [38]. Later, Soll, in 2008, described a limited excision procedure, consisting of selective resection of the sinus by means of scalpel or scissors, with a recurrence rate of $5 \%$ after a median follow-up of 2 years, and a median time off work of 2 weeks, and of 5 weeks to wound healing [39]. Gips' "targeted procedure" is also based on the same sound principles of Bascom, and conveniently employs trephines or disposable biopsy punches of various diameters instead of a small scalpel to excise the pits and debride the sinus cavity [40]. In his first analysis on 1,358 patients, Gips reported a recurrence rate of $6.5,13.2$, and $16.2 \%$ at 1-, 5-, and 10-year follow-up, respectively. Despite the high recurrence rate, the strength of this technique lies in its repeatability $(85 \%$ of the patients cured by one procedure, $95 \%$ by a second). All these minimally invasive techniques require solid experience and expertise in order not to leave behind any untreated PD.

The meta-analysis by Enriquez-Navascues et al. [48] found four papers [87-90] comparing open limited excision (sinusectomy) or unroofing (sinotomy); although recurrence rate did not differ, all other outcomes favored the limited approach.

More recently, in a RCT comparing conservative sinusectomy and excision with primary "off-midline" closure, Popeskou et al. [44] prematurely stopped their study because of adverse outcomes in the sinusectomy group, since these patients were associated to slower wound healing after three weeks, compared to primary closure.

In 2014, Milone et al. [42] and Meinero et al. [41] independently proposed an endoscopic approach to chronic PD (VAAPS and endoscopic pilonidal sinus treatment [EPSiT], respectively). Both techniques, while merging the now longlasting principles of "targeted procedure" with technology, seem to be associated with a faster postoperative recovery and wound healing, quicker return to normal daily activities, and higher patient satisfaction when compared to traditional surgical techniques [46].

In a randomized comparison between VAAPS and Bascom cleft lift [45], VAAPS implied a shorter time off work and lower postoperative infection rate, less pain, and higher patient satisfaction. Although these results are encouraging, less is known about the long-term recurrence rate after treatment using endoscopic techniques. Giarratano et al. [91], in a long-term prospective assessment, achieved a recurrence rate of $7.8 \%$ with a median follow-up of 25 months.

Another long-term randomized study assessed the 5-year recurrence rate, confirming that this was similar in both groups (endoscopic vs. conventional Bascom cleft lift procedure) [45]. Different results were obtained by Romanszyn et al. [92] in a nonrandomized research comparing endoscopic treatment and Limberg flap to treat complicated PD. The endoscopic procedure had a significantly lower success rate than the Limberg flap procedure, but a lower risk of postoperative complications.

Recently, several systematic reviews and meta-analyses confirmed the feasibility and safety of the endoscopic techniques, associated with a low recurrence rate, a good complete healing rate, and good patient satisfaction [93, 94]. In any case, further investigations are needed.

Panel statement: minimally invasive treatments are validated techniques that should be the treatment of choice in case of limited pilonidal disease (single pit or multiple pits on the midline). [complete agreement at 2 nd round].

\section{Management of recurrent pilonidal disease}

\section{The management of recurrent pilonidal sinus is similar to "de novo" presentation (1C)}

Recurrence can be defined as the additional outbreak of signs and symptoms of PD after a disease-free interval following complete wound healing. Risk factors for recurrence are adolescence, sinus number, cavity diameter, and primary closure $[95,96]$.

The surgical treatment of patients with recurrent disease does not differ from the surgical treatment of primary PD. In case of a recurrence with an abscess, incision and drainage prevail, while in case of chronic recurrent PD, a flap based procedure may be indicated following sinus excision with scarring.

In a randomized evaluation of recurrent $\mathrm{PD}$ comparing Limberg flap and modified asymmetric Limberg flap, Cihan et al. [97] demonstrated that a modified asymmetric Limberg flap was associated with a lower infection rate, shorter hospital stay, and shorter time off work, with a trend toward less recurrence after modified asymmetric Limberg flap.

In 2019, Meinero et al. [98] completed a multicenter prospective study on 122 patients with recurrent PD treated with EPSiT, showing a complete healing rate of $95 \%$ and a recurrence rate of $5.1 \%$, while time off work was 3 days. Similar results were also obtained by Manigrasso et al. [99] in a retrospective analysis of 63 patients, with a recurrence rate of $4.7 \%, 11.7 \%$, and $23 \%$ after 1,3 , and 5 years, respectively. The rate of incomplete wound healing was $4.7 \%$, and time off work was 3.5 days.

Although these results encourage a minimally invasive approach to treat recurrent $\mathrm{PD}$, data in the current literature are still limited.

Panel statement: surgical procedures for recurrent PD do not differ from those of primary PD. Even in the case of recurrence, proper surgical treatment should be tailored to the individual patient. [complete agreement at 2nd round]. 


\section{Perioperative management}

\section{Antibiotics have a limited role in wound infections and recurrence (1B)}

Antibiotics could be useful in three different settings: perioperative prophylaxis, postoperative care, and local treatment. In relation to perioperative prophylaxis, Sondeena et al. [100], in a randomized comparison of a single preoperative dose of $2 \mathrm{~g}$ intravenous (i.v.) cefoxitin vs no cefoxitin, did not demonstrate statistically significant differences in terms of infection and healing rates.

Similar results were obtained by Kundes et al. [101], who compared the preoperative use and the non-use of a single dose of $1 \mathrm{~g}$ (i.v.) cefazolin sodium plus metronidazole $500 \mathrm{mg}$ i.v., within $60 \mathrm{~min}$ before skin incision. Even in this study, the use of prophylactic antibiotics did not significantly impact on SSI and recurrence rates.

On the contrary, data in the literature about the use of antibiotics postoperatively are controversial. In a randomized, double-blinded pilot study, Chaudhuri et al. [102] compared wound infections after excision of pilonidal sinuses and primary closure using either a single pre-operative dose of (i.v.) metronidazole, or both (i.v.) cefuroxime and (i.v.) metronidazole preoperatively, and co-amoxiclav $375 \mathrm{mg}$ orally every $8 \mathrm{~h}$, for 5 postoperative days). The single-drug group was associated with a significantly higher wound infection rate after $2(p<0.0001)$ and 4 weeks $(p=0.03)$.

In a RCT [103], the adoption of clindamycin as an adjunct to excision and primary closure translated into a shorter wound healing time both in case of excision and primary closure, and of excision alone. On the other hand, a recent review of 7 studies, totalling 690 patients, showed no advantage when single-dose prophylaxis was compared with no prophylaxis or to a long course of antibiotics in several single- and double-coverage antibiotic regimens [104].

In relation to the efficiency of local antibiotics, data are limited and conflicting. In a randomized trial, Yetim et al. [105] compared the use of oral postoperative antibiotics for 7 days and the placement of gentamicin-absorbed collagen sponges after pilonidal sinus excision and primary closure. The use of gentamicin-absorbed collagen sponges was associated to a lower infection and recurrence rate, and a shorter hospital stay. Similar results were obtained when comparing primary closure and gentamicin sponge vs. secondary healing [106]. On the contrary, a randomized comparative study on primary closure with or without gentamicin-collagen sponges showed no differences between the two treatments [107].

Recently, a review and meta-analysis of the use of collagen showed less wound infections, but no significant influence on wound healing or disease recurrence [108].
Panel statement: pre- and postoperative antibiotic use do not significantly impact wound infection and dehiscence rates

\section{Hair removal from the natal cleft may be useful as an additional treatment after excision of the pilonidal sinus (1C)}

The rationale for hair removal lies in the eradication of risk factors for the development of PD. Light amplification by stimulated emission of radiation (LASER) epilation may be useful as an additional treatment after excisional surgery. Several studies have demonstrated a lower postoperative recurrence rate in case of hair removal, after complete wound healing $[109,110]$. On the contrary, the employment of a razor (shaving) in the immediate postoperative period seemed to be associated with a higher recurrence rate [111].

However, data about the real advantages of hair removal as an adjunct to excisional surgery are controversial. A prospective RCT, comparing pre- and postoperative LASER hair removal with no hair removal, failed to demonstrate that LASER hair removal reduced the recurrence rate [112]. However, in this RCT, LASER epilation was associated with less postoperative pain and higher patient satisfaction than surgery alone.

On the other hand, a randomized comparison between LASER epilation and hair removal by means of a razor or depilatory creams, demonstrated a lower recurrence rate if LASER was used [113]. Recently, the results of a systematic review of the literature on postoperative hair removal showed that postoperative LASER epilation was associated with a lower recurrence rate than razor/cream depilation. The recurrence rate of PD was 9.3\% (34 out of 366 patients) in patients who had LASER hair removal, 23.4\% (36 out of 154 patients) in those who had razor shaving/cream depilation, and 19.7\% (85 out of 431 patients) in those who had no hair removal after surgery [114]. Nevertheless, current evidence of the efficacy of hair removal after pilonidal surgery is still low and needs additional studies.

Panel statement: in hirsute patients, postoperative epilation is recommended. [complete agreement at 2 nd round]

\section{Conclusions}

The validated surgical techniques for the management of PD are open healing, off-midline primary closure, and minimally invasive "targeted" techniques (sinusectomy and endoscopic approaches).

Surgical management should be individualized and tailored according to the individual PD. 
A key challenge for the future will be to develop and validate a classification of $\mathrm{PD}$, which should then assist and guide the surgeon in the management of this disease. Although many surgical aspects of the treatment of PD remain controversial, the panelists recommend the adoption of minimally invasive surgery in cases of limited PD (single/ multiple pits on the midline), and traditional open healing for complex cases.

Funding Open access funding provided by Università degli Studi di Roma La Sapienza within the CRUI-CARE Agreement.

\section{Declarations}

Conflict of interest The authors declare that they have no conflict of interest.

Ethical approval Not required.

Informed consent Not required.

Open Access This article is licensed under a Creative Commons Attribution 4.0 International License, which permits use, sharing, adaptation, distribution and reproduction in any medium or format, as long as you give appropriate credit to the original author(s) and the source, provide a link to the Creative Commons licence, and indicate if changes were made. The images or other third party material in this article are included in the article's Creative Commons licence, unless indicated otherwise in a credit line to the material. If material is not included in the article's Creative Commons licence and your intended use is not permitted by statutory regulation or exceeds the permitted use, you will need to obtain permission directly from the copyright holder. To view a copy of this licence, visit http://creativecommons.org/licenses/by/4.0/.

\section{References}

1. Sion-Vardy N, Osyntsov L, Cagnano E, Osyntsov A, Vardy D, Benharroch D (2009) Unexpected location of pilonidal sinuses. Clin Exp Dermatol 34(8):599-601

2. Søndenaa K, Andersen E, Nesvik I, Søreide JA (1995) Patient characteristics and symptoms in chronic pilonidal sinus disease. Int J Colorectal Dis 10(1):39-42

3. Segre D, Pozzo M, Perinotti R, Roche B; Italian Society of Colorectal Surgery (2015) The treatment of pilonidal disease: guidelines of the Italian society of colorectal surgery (SICCR). Tech Coloproctol 19(10):607-613

4. Johnson EK, Vogel JD, Cowan ML, Feingold DL, Steele SR; Clinical Practice Guidelines Committee of the American Society of Colon and Rectal Surgeons (2019) The American society of colon and rectal surgeons' clinical practice guidelines for the management of pilonidal disease. Dis Colon Rectum 62(2):146-157

5. Fink A, Kosecoff J, Chassin M, Brook RH (1984) Consensus methods: characteristics and guidelines for use. Am J Public Health 74(9):979-983

6. Guyatt G, Gutterman D, Baumann MH, Addrizzo-Harris D, Hylek EM, Phillips B, Raskob G, Lewis SZ, Schünemann H (2006) Grading strength of recommendations and quality of evidence in clinical guidelines: report from an american college of chest physicians task force. Chest 129(1):174-181

7. Likert R (1932) A technique for the measurement of attitudes. Arch Psychol 140:1-55

8. Beal EM, Lee MJ, Hind D, Wysocki AP, Yang F, Brown SR (2019) A systematic review of classification systems for pilonidal sinus. Tech Coloproctol 23(5):435-443

9. Lapsekill E, Coskun M, Oztas M, Urkan M, Can MF (2013) A classification proposal for the sacrococcygeal pilonidal sinus disease (SPSD). Eur Surg Res [Internet]. 50(SUPPL. 1):144. https:// www.karger.com/Article/Pdf/351978. (Accessed 27 Jul 2020)

10. Irkörücü $O$ (2016) Management for pilonidal disease: before you compare, use a classification system. Asian J Surg 39(4):260 261. https://doi.org/10.1016/j.asjsur.2016.04.004

11. Doll D, Vassiliu P (2018) Another pilonidal classificationPLLATIN. Pilonidal Sinus J [Internet]. 4(1): 1-3. https://www. pilonidal.com.au/ojs/ojs-3.1.0-1/index.php/PSJ/article/view/ 10. (Accessed 27 Jul 2020)

12. Guner A, Cekic AB, Boz A, Turkyilmaz S, Kucuktulu U (2016) A proposed staging system for chronic symptomatic pilonidal sinus disease and results in patients treated with stage-based approach. BMC Surg 16:18

13. Tezel E (2007) A new classification according to navicular area concept for sacrococcygeal pilonidal disease. Colorectal Dis 9(6):575-576

14. Awad MM, Elbaset AA, Ebraheem S, Tantawy E, Elhafez MA, Elsayed AM (2009) A scoring system as a method to evaluate pilonidal sinus disease to make an easy decision for its management. Indian J Plast Surg 42(1):43-48

15. Karakaş DÖ, Yılmaz İ, Hazer B, Dandin Ö, Sücüllü İ, Sinüs P et al (2017) Congress of Turkish colon and rectal surgery on 19-23. Color Dis [Internet]. 27:65-6. https://www.journalage nt.com/krhd/pdfs/KRHD_27_2_65_66.pdf. (Accessed 27 Jul 2020)

16. Nelson JM, Billingham RP (2007) Pilonidal disease and hidradenitis suppurativa. In: Wolff BG, Fleshman JW, Beck DE et al (eds) The ASCRS textbook of colon and rectal surgery, 1st edn. Springer, pp 228-235

17. Steele SR, Hull TL, Read TE et al (2016) The ASCRS textbook of colon and rectal surgery, 3rd edn. Springer

18. Youssef AT (2015) The value of superficial parts and endoanal ultrasonography in evaluating pilonidal disease and exclusion of perianal sepsis. J Ultrasound 18(3):237-243

19. Iesalnieks I, Ommer A, Petersen S, Doll D, Herold A (2016) German national guideline on the management of pilonidal disease. Langenbecks Arch Surg 401(5):599-609

20. Fitzpatrick EB, Chesley PM, Oguntoye MO, Maykel JA, Johnson EK, Steele SR (2014) Pilonidal disease in a military population: how far have we really come? Am J Surg 207:907-914

21. Vahedian J, Nabavizadeh F, Nakhaee N, Vahedian M, Sadeghpour A (2005) Comparison between drainage and curettage in the treatment of acute pilonidal abscess. Saudi Med J 26:553-555

22. Jackson D, Bowden J, Baker R (2010) How does the DerSimonian and Laird procedure for random effects meta-analysis compare with its more efficient but harder to compute counterparts? J Stat Plan Inference 140(4):961-970

23. Garg P, Menon GR, Gupta V (2016) Laying open (deroofing) and curettage of sinus as treatment of pilonidal disease: a systematic review and meta-analysis. ANZ J Surg 86(1-2):27-33

24. Matter I, Kunin J, Schein M, Eldar S (1995) Total excision versus non-resectional methods in the treatment of acute and chronic pilonidal disease. Br J Surg 82(6):752-753

25. Hosseini SV, Bananzadeh AM, Rivaz M et al (2006) The comparison between drainage, delayed excision and primary closure with excision and secondary healing in management of pilonidal abscess. Int J Surg 4:228-231 
26. Javed MA, Fowler H, Jain Y, Singh S et al (2016) Comparison of conventional incision and drainage for pilonidal abscess versus novel endoscopic pilonidal abscess treatment (EPAT). Tech Coloproctol 20(12):871-873

27. Jain Y, Javed MA, Singh S, Rout S et al (2017) Endoscopic pilonidal abscess treatment: a novel approach for the treatment of pilonidal abscess. Ann R Coll Surg Engl 99(2):134-136

28. Gencosmanoglu R, Inceoglu R (2005) Modified lay-open (Incision, curettage, partial lateral wall excision and marsupialization) versus total excision with primary closure in the treatment of chronic sacrococcygeal pilonidal sinus. Int J Colorectal Dis 20(5):415-422

29. Jamal A, Shamim M, Hashmi F, Qureshi MI (2009) Open excision with secondary healing versus rhomboid excision with Limberg transposition flap in the management of sacrococcygeal pilonidal disease. J Pak Med Assoc 59(3):157-160

30. Fazeli MS, Adel MG, Lebaschi AH (2006) Comparison of outcomes in Z-plasty and delayed healing by secondary intention of the wound after excision of the sacral pilonidal sinus: results of a randomized, clinical trial. Dis Colon Rectum 49(12):1831-1836

31. Sakr M, Habib M, Shaheed AA (2006) Assessment of Karydakis technique as compared with midline closure for the management of chronic pilonidal sinus. J Pelvic Med Surg 12:201-206

32. Elshazly W, Said K (2012) Clinical trial comparing excision and primary closure with modified Limberg flap in the treatment of uncomplicated sacrococcygeal pilonidal disease. Alex J Med 48:13-18

33. Akca T, Colak T, Urtunsoy B, Kanik A, Aydin S (2005) Randomized clinical trial comparing primary closure with the Limberg flap in the treatment of primary sacrococcygeal pilonidal disease. Br J Surg 92:1081-1084

34. Lord PH, Millar DM (1965) Pilonidal sinus: a simple treatment. Br J Surg 52:298-300

35. Bascom J (1980) Pilonidal disease: origin from follicles of hairs and results of follicle removal as treatment. Surgery 87(5):567-572

36. Bascom J (1983) Pilonidal disease: long-term results of follicle removal. Dis Colon Rectum 26(12):800-807

37. Bascom J (2008) Surgical treatment of pilonidal disease. BMJ 336(7649):842-843

38. Oncel N, Kurt M, Kement M, Colak E, Eser M, Uzun H (2002) Excision and marsupialization versus sinus excision for the treatment or limited chronic pilonidal disease: a prospective, randomized trial. Tech Coloproctol 6:165-169

39. Soll C, Hahnloser D, Dindo D, Clavien PA, Hetzer F (2008) A novel approach for treatment of sacrococcygeal pilonidal sinus: less is more. Int J Colorectal Dis 23(2):177-180

40. Gips M, Melki Y, Salem L, Weil R (2008) Sulkes J (2008) Minimal surgery for pilonidal disease using trephines: description of a new technique and long-term outcomes in 1,358 patients. Dis Colon Rectum 51(11):1656-1662

41. Meinero P, Mori L, Gasloli G (2014) Endoscopic pilonidal sinus treatment (EPSiT). Tech Coloproctol 18(4):389-392

42. Milone M, Musella M, Di Spiezio SA, Bifulco G, Salvatore G, Sosa Fernandez LM, Bianco P, Zizolfi B, Nappi C, Milone F (2014) Video-assisted ablation of pilonidal sinus: a new minimally invasive treatment-a pilot study. Surgery 155(3):562-566

43. Milone M, Sosa Fernandez LM, Vertaldi S, De Simone G, Servillo G, Manigrasso M, De Palma GD (2020) Video-assisted ablation of pilonidal sinus - a video vignette. Colorectal Dis 22(5):597-598

44. Popeskou SG, Pravini B, Panteleimonitis S, Vajana AFDT, Vanoni A, Schmalzbauer M, Posabella A, Christoforidis D (2020) Conservative sinusectomy vs. excision and primary off-midline closure for pilonidal disease: a randomized controlled trial. Int J Colorectal Dis 35(7):1193-1199

45. Milone M, Fernandez LM, Musella M, Milone F (2016) Safety and efficacy of minimally invasive video-assisted ablation of pilonidal sinus: a randomized clinical trial. JAMA Surg 151(6):547-553

46. Milone M, Velotti N, Manigrasso M, Vertaldi S, Di Lauro K, De Simone G, Cirillo V, Maione F, Gennarelli N, Sosa Fernandez LM, De Palma GD (2020) Long-term results of a randomized clinical trial comparing endoscopic versus conventional treatment of pilonidal sinus. Int J Surg 74:81-85

47. Milone M, Velotti N, Manigrasso M, Milone F, Sosa Fernandez LM, De Palma GD (2019) Video-assisted ablation of pilonidal sinus (VAAPS) versus sinusectomy for treatment of chronic pilonidal sinus disease: a comparative study. Updates Surg 71(1):179-183

48. Al-Khamis A, McCallum I, King PM, Bruce J (2010) Healing by primary versus secondary intention after surgical treatment for pilonidal sinus. Cochrane Database Syst Rev 1:CD006213.pub3

49. Enriquez-Navascues JM, Emparanza JI, Alkorta M, Placer C (2014) Meta-analysis of randomized controlled trials comparing different techniques with primary closure for chronic pilonidal sinus. Tech Coloproctol 18(10):863-872

50. Milone M, Velotti N, Manigrasso M, Anoldo P, Milone F, De Palma GD (2018) Long-term follow-up for pilonidal sinus surgery: a review of literature with meta-analysis. Surgeon 16(5):315-320

51. Karydakis GE (1992) Easy and successful treatment of pilonidal sinus after explanation of its causative process. Aust NZ J Surg 62:385-389

52. Keshvari A, Keramati MR, Fazeli MS, Kazemeini A, Meysamie A, Nouritaromlou MK (2015) Karydakis flap versus excisiononly technique in pilonidal disease. J Surg Res 198(1):260-266

53. Gwynn BR (1986) Use of the rhomboid flap in pilonidal sinus. Ann R Coll Surg Engl 68:40-41

54. Sevinç B, Karahan Ö, Okuş A, Ay S, Aksoy N, Şimşek G (2016) Randomized prospective comparison of midline and offmidline closure techniques in pilonidal sinus surgery. Surgery 159:749-754

55. Tokac M, Dumlu EG, Aydin MS, Yalcin A, Kilic M (2015) Comparison of modified Limberg flap and Karydakis flap operations in pilonidal sinus surgery: prospective randomized study. Int Surg 100:870-877

56. Arslan K, Said Kokcam S, Koksal H, Turan E, Atay A, Dogru O (2014) Which flap method should be preferred for the treatment of pilonidal sinus? A prospective randomized study. Tech Coloproctol 18:29-37

57. Bessa SS (2013) Comparison of short-term results between the modified Karydakis flap and the modified Limberg flap in the management of pilonidal sinus disease: a randomized controlled study. Dis Colon Rectum 56:491-498

58. Sahebally SM, McMahon G, Walsh SR, Burke JP (2019) Classical Limberg versus classical Karydakis flaps for pilonidal disease- an updated systematic review and meta-analysis of randomized controlled trials. Surgeon 17(5):300-308

59. Prassas D, Rolfs TM, Schumacher FJ, Krieg A (2018) Karydakis flap reconstruction versus Limberg flap transposition for pilonidal sinus disease: a meta-analysis of randomized controlled trials. Langenbecks Arch Surg 403(5):547-554

60. Gavriilidis P, Bota E (2019) Limberg flap versus Karydakis flap for treating pilonidal sinus disease: a systematic review and metaanalysis. Can J Surg 62(2):131-138

61. Bascom J (1987) Repeat pilonidal operations. Am J Surg 154(1):118-122 
62. Bascom J, Bascom T (2002) Failed pilonidal surgery: new paradigm and new operation leading to cures. Arch Surg 137:1146-1150

63. Bascom J, Bascom T (2007) Utility of the cleft lift procedure in refractory pilonidal disease. Am J Surg 193:606-609

64. Gendy AS, Glick RD, Hong AR et al (2011) A comparison of the cleft lift procedure vs. wide excision and packing for the treatment of pilonidal disease in adolescents. J Pediatr Surg 46:1256-1259

65. Senapati A, Cripps NP, Flashman K, Thompson MR (2011) Cleft closure for the treatment of pilonidal sinus disease. Colorectal Dis 13:333-336

66. Ortega PM, Baixauli J, Arredondo J et al (2014) Is the cleft lift procedure for non-acute sacrococcygeal pilonidal disease a definitive treatment? Long-term outcomes in 74 patients. Surg Today 44:2318-2322

67. Guner A, Boz A, Faruk Okzan O, Ileli O, Kece C, Reis E (2013) Limberg flap versus Bascom cleft lift techniques for sacrococcygeal pilonidal sinus: prospective, randomized trial. World J Surg 37:2074-2080

68. Schoeller T, Wechselberger G, Otto A, Papp C (1997) Definitive surgical treatment of complicated recurrent pilonidal disease with a modified fasciocutaneous V-Y advancement flap. Surgery 121:258-263

69. Nursal TZ, Ezer A, Caliskan K, Torer N, Belli S, Moray G (2010) Prospective randomized controlled trial comparing V-Y advancement flap with primary suture methods in pilonidal disease. Am J Surg 199:170-177

70. Eryilmaz R, Okan I, Coskun A, Bas G, Sahin M (2009) Surgical treatment of complicated pilonidal sinus with a fasciocutaneous V-Y advancement flap. Dis Colon Rectum 52:2036-2040

71. Thompson RM, Senapati A, Kitchen PRB (2010) Pilonidal sinus disease. In: Givel JC, Mortensen NJ, Roche B (eds) Anorectal and colonic diseases: a practical guide to their management, 3rd edn. Springer Verlag, pp 373-386

72. Tocchi A, Mazzoni G, Bononi M et al (2008) Outcome of chronic pilonidal disease treatment after ambulatory plain midline excision and primary suture. Am J Surg 196:28-33

73. Milone M, Musella M, Salvatore G, Leongito M, Milone F (2011) Effectiveness of a drain in surgical treatment of sacrococcygeal pilonidal disease: results of a randomized and controlled clinical trial on 803 consecutive patients. Int J Colorectal Dis 26:1601-1607

74. Gurer A, Gomceli I, Ozdogan M, Ozlem N, Sozen S, Aydin R (2005) Is routine cavity drainage necessary in Karydakis flap operation? A prospective, randomized trial. Dis Colon Rectum 48:1797-1799

75. Erdem E, Sungurtekin U, Neşşar M (1998) Are postoperative drains necessary with the Limberg flap for treatment of pilonidal sinus? Dis Colon Rectum 41:1427-1431

76. Milone M, Di Minno MND, Musella M et al (2013) The role of drainage after excision and primary closure of pilonidal sinus: a meta-analysis. Tech Coloproctol 17:625-630

77. Muzi MG, Milito G, Nigro C, Cadeddu F, Farinon AM (2008) A modification of primary closure for the treatment of pilonidal disease in day-care setting. Colorectal Dis 11:84-88

78. Berthier C, Bérard E, Meresse T, Grolleau JL, Herlin C, Chaput B (2019) A comparison of flap reconstruction vs. the laying open technique or excision and direct suture for pilonidal sinus disease: a meta-analysis of randomised studies. Int Wound $\mathbf{J}$ 16(5):1119-1135

79. National Institute for Health and Care Excellence. Chronic wounds: advanced wound dressings and antimicrobial dressings. London, UK: NICE. https://www.nice.org.uk/advice/esmpb2/ resources/chronic-wounds-advanced-wound-dressings-and-antim icrobialdressingspdf-1502609570376901
80. Viciano V, Castera JE, Medrano J et al (2000) Effect of hydrocolloid dressings on healing by second intention after excision of pilonidal sinus. Eur J Surg 166:229-232

81. Grandjean JP, Al Nashawati G (1996) Traitement de la maladie pilonidale par excision large et cicatrisation dirigée. Lyon Chir 92:292-295

82. SICCR Pilonidalis Study Group: Giannini I, Andreoli R, Bianchi FP et al (2019) Effectiveness of topical use of Lietofix ${ }^{\circledR}$ in wound healing after pilonidalis sinus excision: a multicenter study by the Italian Society of Colorectal Surgery (SICCR). Tech Coloproctol 23(4):373-378

83. Sadati L, Froozesh R, Beyrami A, Khaneghah ZN, Elahi SA, Asl MF, Salehi T (2019) A comparison of three dressing methods for pilonidal sinus surgery wound healing. Adv Skin Wound Care 32(7): $1-5$

84. Brolmann FE, Ubbink DT, Nelson EA, Munte K, van der Horst CMAM, Vermeulen H (2012) Evidence-based decisions for local and systemic wound care. Br J Surg 99:1172-1183

85. Mohammadi S, Nasiri S, Mohammadi MH et al (2017) Evaluation of platelet-rich plasma gel potential in acceleration of wound healing duration in patients underwent pilonidal sinus surgery: a randomized controlled parallel clinical trial. Transfus Apher Sci 56(2):226-232

86. Biter UL, Beck GMN, Mannaerts G, Stok MM, van der Ham AC, Grotenhuis BA (2014) The use of negative-pressure wound therapy in pilonidal sinus disease: a randomized controlled trial comparing negative-pressure wound therapy versus standard open wound care after surgical excision. Dis Colon Rectum 57:1406-1411

87. Thompson MR, Senapati A, Kitchen P (2011) Simple day-case surgery for pilonidal sinus disease. Br J Surg 98:198-209

88. Ortiz HH, Marti J, Sitges A (1977) Pilonidal sinus. A claim for simple track incision. Dis Colon Rectum 20:325-328

89. Gupta PJ (2004) A randomized study between excision and marsupialization and radiofrequency sinus excision in sacrococcygeal pilonidal disease. Curr Surg 61:307-312

90. Mohamed HA, Kadry I, Adly S (2005) Comparison between three therapeutic modalities for non-complicated pilonidal sinus disease. Surgeon 3:73-77

91. Giarratano G, Toscana C, Shalaby M, Buonomo O, Petrella G, Sileri P (2017) Endoscopic pilonidal sinus treatment long-term results of a prospective series. JSLS 21(3):e2017.00043

92. Romaniszyn M, Swirta JS, Walega PJ (2020) Long-term results of endoscopic pilonidal sinus treatment vs Limberg flap for treatment of difficult cases of complicated pilonidal disease: a prospective, nonrandomized study. Colorectal Dis 22(3):319-324

93. Emile SH, Elfeki H, Shalaby M, Sakr A, Giaccaglia V, Sileri P, Wexner SD (2018) Endoscopic pilonidal sinus treatment: a systematic review and meta-analysis. Surg Endosc 32(9):3754-3762

94. Tien T, Athem R, Arulampalam T (2018) Outcomes of endoscopic pilonidal sinus treatment (EPSiT): a systematic review. Tech Coloproctol 22(5):325-331

95. Onder A, Girgin S, Kapan M et al (2012) Pilonidal sinus disease: risk factors for postoperative complications and recurrence. Int Surg 97:224-229

96. Brusciano L, Limongelli P, Del Genio G, Tolone S, Amoroso V, Docimo G (2015) D-shape asymmetric excision of sacrococcygeal pilonidal sinus with primary closure, suction drain, and subcuticular skin closure: an analysis of risks factors for longterm recurrence. Surg Innov 22:143-148

97. Cihan A, Ucan BH, Comert M, Cesur A, Cakmak GK, Tascilar O (2006) Superiority of asymmetric modified Limberg flap for surgical treatment of pilonidal disease. Dis Colon Rectum 49(2):244-249 
98. Meinero P, La Torre M, Lisi G, Stazi A, Carbone A, Regusci L, Fasolini F (2019) Endoscopic pilonidal sinus treatment (EPSiT) in recurrent pilonidal disease: a prospective international multicenter study. Int J Colorectal Dis 34(4):741-746

99. Manigrasso M, Velotti N, Sosa Fernandez LM, Vertaldi S, Maione F, Gennarelli N, Dinuzzi VP, Musella M, De Palma GD, Milone M (2021) Endoscopic approach to recurrent pilonidal sinus: A retrospective analysis. J Laparoendosc Adv Surg Tech 31:1-5. https://doi.org/10.1089/lap.2020.0252

100. Sondenaa K, Nesvik I, Gullaksen FP et al (1995) The role of cefoxitin prophylaxis in chronic pilonidal sinus treated with excision and primary suture. J Am Coll Surg 180:157-160

101. Kundes MF, Cetin K, Kement M et al (2016) Does prophylactic antibiotic reduce surgical site infections after rhomboid excision and Limberg flap for pilonidal disease: a prospective randomized double blind study. Int J Colorectal Dis 31:1089-1091

102. Chaudhuri A, Bekdash BA, Taylor AL (2006) Single-dose metronidazole vs. 5-day multi-drug antibiotic regimen in excision of pilonidal sinuses with primary closure: a prospective, randomized, double-blinded pilot study. Int J Colorectal Dis 21:688-692

103. Kronborg O, Christensen K, Zimmermann-Nielsen C (1985) Chronic pilonidal disease: a randomized trial with a complete 3-year follow-up. Br J Surg 72:303-304

104. Mavros MN, Mitsikostas PK, Alexiou VG, Peppas G, Falagas ME (2013) Antimicrobials as an adjunct to pilonidal disease surgery: a systematic review of the literature. Eur J Clin Microbiol Infect Dis 32:851-858

105. Yetim I, Ozkan OV, Dervişoglu A, Erzurumlu K, Canbolant E (2010) Effect of gentamicin-absorbed collagen in wound healing in pilonidal sinus surgery: a prospective randomized study. J Int Med Res 38(3):1029-1033

106. Rao MM, Zawislak W, Kennedy R, Gilliland R (2010) A prospective randomised study comparing two treatment modalities for chronic pilonidal sinus with a 5-year follow-up. Int J Colorectal Dis 25:395-400
107. Andersson RE, Lukas G, Skullman S, Hugander A (2010) Local administration of antibiotics by gentamicin-collagen sponge does not improve wound healing or reduce recurrence rate after pilonidal excision with primary suture: a prospective randomized controlled trial. World J Surg 34:3042-3048

108. Nguyen AL, Pronk AA, Furnée EJ, Pronk A, Davids PH, Smakman N (2016) Local administration of gentamicin collagen sponge in surgical excision of sacrococcygeal pilonidal sinus disease: a systematic review and meta-analysis of the literature. Tech Coloproctol 20:91-100

109. Solla JA, Rothenberger DA (1990) Chronic pilonidal disease: an assessment of 150 cases. Dis Colon Rectum 33:758-761

110. Al-Naami MY (2005) Outpatient pilonidal sinotomy complemented with good wound and surrounding skin care. Saudi Med J 26:285-288

111. Petersen S, Wietelmann K, Evers T, Hüser N, Matevossian E, Doll D (2009) Long-term effects of postoperative razor epilation in pilonidal sinus disease. Dis Colon Rectum 52:131-134

112. Demircan F, Akbulut S, Yavuz R, Agtas H, Karabulut K, Yagmur Y (2015) The effect of laser epilation on recurrence and satisfaction in patients with sacrococcygeal pilonidal disease: a prospective randomized controlled trial. Int J Clin Exp Med 8(2):2929-2933

113. Ghnnam WM, Hafez DM (2011) Laser hair removal as adjunct to surgery for pilonidal sinus: our initial experience. J Cutan Aesthet Surg 4(3):192-195

114. Pronk AA, Eppink L, Smakman N, Furnee EJB (2018) The effect of hair removal after surgery for sacrococcygeal pilonidal sinus disease: a systematic review of the literature. Tech Coloproctol 22(1):7-14

Publisher's Note Springer Nature remains neutral with regard to jurisdictional claims in published maps and institutional affiliations. 